\title{
Predictive clinical and laboratory parameters for serum zinc and copper in rheumatoid arthritis
} HELENA MUSSALO-RAUHAMAA, ${ }^{1}$ YRJÖ T KONTTINEN, ${ }^{2}$ JARI LEHTO,
AND VISA HONKANEN ${ }^{3}$

From the ${ }^{1}$ Department of Public Health, University of Helsinki, Helsinki, Finland; the ${ }^{2}$ Division of Rheumatic Diseases, Fourth Department of Medicine, Helsinki University Central Hospital, Helsinki; Finland; and the ${ }^{3}$ Children's Hospital, Helsinki University Central Hospital, Helsinki, Finland

SUMMARY Zinc and copper have important effects on $\mathrm{T}$ cell mediated immunity and on neutrophil function, but it is not known how the causes or effects, or both, of low serum zinc and high serum copper relate to the clinical picture of rheumatoid arthritis (RA). In this study serumpo zinc and copper determined by flame atomic absorption spectrometry and 30 other clinical, immunological, and laboratory parameters in 60 patients with RA were analysed by stepwise multiple linear regression analysis. Joint score index, rheumatoid factor titre, seropositivity $\overrightarrow{0}$ haemoglobin, and $\mathrm{C}$ reactive protein (CRP) were among the nine independent variables which together predicted $73 \%$ of the serum zinc variation. This suggests that there is an association? between the immune-inflammatory rheumatoid process and the serum zinc concentration. CRP alone had only a 3\% independent predicting value for serum zinc, however. This suggests that metallothionein mediated sequestration in the liver, induced by interleukin 1 , is not an importain $\infty^{\circ}$

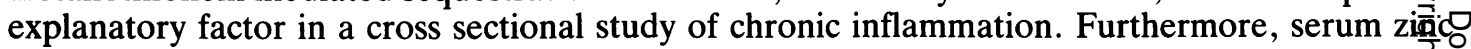
did not have any predictive value at all for serum copper concentration. This does not support tffes hypothesis suggesting that serum zinc deficiency leads to high serum copper by inducingo gastrointestinal metallothionein and high caeruloplasmin.

After iron, zinc and copper are the second and third most abundant trace elements in the human body. Zinc deficiency seems to enhance absorption of copper from food and to increase serum copper by inducing intestinal metallothionein and liver caeruloplasmin. ${ }^{1}$ The simultaneous use of serum copper and zinc measurements has been advocated for the clinical assessment of certain diseases. ${ }^{2}$ Serum zinc and copper may reflect the dietary content and availability of these elements, their absorption from the gastrointestinal tract, or excretion via urine and sweat. ${ }^{3}$ Furthermore, metallothionein dependent uptake and storage may also change serum zinc concentrations. ${ }^{4}$ An important regulatory factor may be activation of the phagocytic leucocytes, inducing them to secrete hormonelike substances and leading to an abrupt hepatic sequestration of zinc. ${ }^{4}$ More recently, interleukin 1 has been recognised as the primary mediator of the

Accepted for publication 1 March 1988.

Correspondence to Dr Helena Mussalo-Rauhamaa, Department of Public Health, Haartmanink 3, SF-00290 Helsinki, Finland. acute phase response and has been suggested as $\mathrm{a}^{3}$ possible cause of the changes of the serum trace elements associated with the acute phase response. In contrast with iron, serum zinc and copper have aroused relatively little interest. ${ }^{6}$ In this study we analysed possible associations between serum zine or copper concentrations and various clinical varies ables in a group of patients with well characterisecक rheumatoid arthritis using stepwise multiple lineaş regression analysis. ${ }^{7}$

\section{Patients and methods}

PATIENTS

In 1985-6, at the Division of Rheumatic Diseases Fourth Department of Medicine, Helsinki Univer ${ }^{\omega}$ sity, Finland, we studied 60 patients with classical of definite rheumatoid arthritis (RA) according t\& American Rheumatism Association (ARA criteria. ${ }^{8}$ Patients receiving zinc or copper sup plementation were excluded. The mean number of ARA criteria was 6.5 (range 5-8). Most patients had seropositive erosive RA, with erosions observed if 
55 patients, and a positive rheumatoid factor titre had been recorded in a Waaler-Rose or latex agglutination test at least twice during the course of the disease in 38 of the 60 patients. At the time of study, however, low or negative, slightly raised, and strong positive Waaler-Rose titres were recorded in 51, six, and three patients respectively, the corresponding figures for latex agglutination test being 51 , eight, and one.

According to the functional classification of the ARA 45 of our patients had function adequate for normal activities despite the handicap of limited movement at one or more joints. ${ }^{9}$ Eight patients had a normal functional status, i.e., ARA class I, whereas seven were severely limited in their ability to perform normal occupational duties or usual self care. Incapacitated ARA class IV patients were excluded from this series.

The mean age of the patients was 53 (range 28-83) years and the mean duration of disease at the time of study 11 (range 1-52) years. Fifty six patients were women and four were men. The mean (SD) height and weight were 164 (6) $\mathrm{cm}$ and 63 (10) kg respectively. All patients were from the Greater Helsinki area.

Patients were asked about their dietary habits, including the consumption of fish, supplementation with selenium, zinc, copper, iron, and vitamins A, $\mathrm{E}$, or C. Cigarette smoking was also recorded. Patients and physicians alike were also asked to make a comprehensive, subjective assessment of the condition of the patient on a five stage scale.

One of our patients was not receiving any drugs at the time of the study, and 26 patients were treated only with non-steroidal anti-inflammatory drugs (NSAIDs) or low dose prednisone $(<6 \mathrm{mg} /$ day $)$, or both. Thirty two of the patients received a slow acting disease modifying drug: eight were receiving sulphasalazine, 15 aurothiomalate injections, six oral auranofin, and three hydroxychloroquine. In addition, three of the patients treated with gold also received hydroxychloroquine. Patients who had been receiving slow acting disease modifying drugs during the previous three months were recorded as being treated. One of our patients received $15 \mathrm{mg}$ prednisone a day for her RA and asthma, but otherwise none of our patients was taking immunosuppressive or cytostatic drugs.

Fifty five patients had morning stiffness lasting for at least one hour. Inflammation was also assessed using standard erythrocyte sedimentation rate $(36$ (SD 23) mm/h), CRP (21 (22) mg/l), and haemoglobin $(123(17) \mathrm{g} / \mathrm{l})$. To characterise the extent of the rheumatoid involvement a joint score index was recorded according to Kaarela's method, ${ }^{10}$ for which purpose involvement was measured by the extent of swelling (except hips and cervical spine, where limitation of movement was recorded). Our patients had a mean (SD) score of 10 (5), the maximum Kaarela score being 23. Involvement of the 'small' peripheral joints (from the wrists to periphery or from the talocrural joint to the periphery, or both,) and of the 'large' joints (namely, elbows, glenohumeral joints, knee joints, hip joints, and cervical spine) was also recorded separately for statistical analysis. According to the occupation reported, $3.6 \%$ of patients were upper white collar personnel, $47 \cdot 2 \%$ lower white collar personnel, $29 \cdot 1 \%$ workers and $20.1 \%$ housewives, students, or pensioners whose earlier occupations were not known. ${ }^{11}$ Control persons younger than 65 years of age were workers at research institutes in the Helsinki area. The over 65 year old controls lived in homes for the elderly.

\section{ELEMENT ANALYSIS}

Venous blood was obtained with stainless steel needles (Neolus, Terumo, Belgium) following an overnight fast. The serum was separated by centrifuging and stored at $-20^{\circ} \mathrm{C}$ until analysis.

Zinc and copper concentrations were determined by flame atomic absorption spectrometry. A single dilution technique was used. ${ }^{12}$ A Perkin-Elmer 5000 spectrometer was used for the atomic absorption determinations. To control analytical quality Seronorm (Nyegaard \& Co, Oslo, Norway) standard reference serum was analysed during every run.

\section{STATISTICAL ANALYSIS}

A BMDP-UCLA 1985 computer program was used for the statistical procedures. The relation between serum zinc and copper concentrations and the different clinical, laboratory, and other parameters was examined by stepwise multiple linear regression analysis in a forward manner. Table 1 shows the

Table 1 Variables used in stepwise regression

\begin{tabular}{ll}
\hline Serum zinc & ARA criteria \\
Serum copper & ARA functional classification \\
Age & ESR \\
Sex & Seropositivity \\
Weight & Erosions \\
Height & CRP \\
Occupation & Haemoglobin \\
Residence & Morning stiffness \\
Fish consumption & Waaler-Rose titre \\
Serum selenium & Latex titre \\
Smoking & Joint score index \\
Supplementation of & Type of joints affected (large, small) \\
iron & Disease duration \\
selenium & Assessment of the condition \\
vitamin A & by the patient \\
vitamin E & by the physicians \\
vitamin C & Drug treatment \\
\hline
\end{tabular}


variables considered. All the data in the text are presented as arithmetic means (SD). In addition, a $t$ test (two sided; separate variance estimate) was used.

\section{Results}

SERUM ZINC AND COPPER CONCENTRATIONS Serum zinc concentrations were lower in patients with RA (mean (SD) $10.2(2.0) \mu \mathrm{mol} / \mathrm{l})$ than in normal controls $(11.9(1.8) \mu \mathrm{mol} / \mathrm{l} ; \mathrm{p}<0.001 ; \mathrm{Fig} 1)$. No age dependence was found in zinc values. The copper concentrations decreased in patients with $\mathrm{RA}$ with increasing age, while in the controls the opposite effect was found. In the group of patients less than 65 years old the mean copper concentration was higher $(23.7(5.3) \mu \mathrm{mol} / \mathrm{l})$ in patients with $\mathrm{RA}$

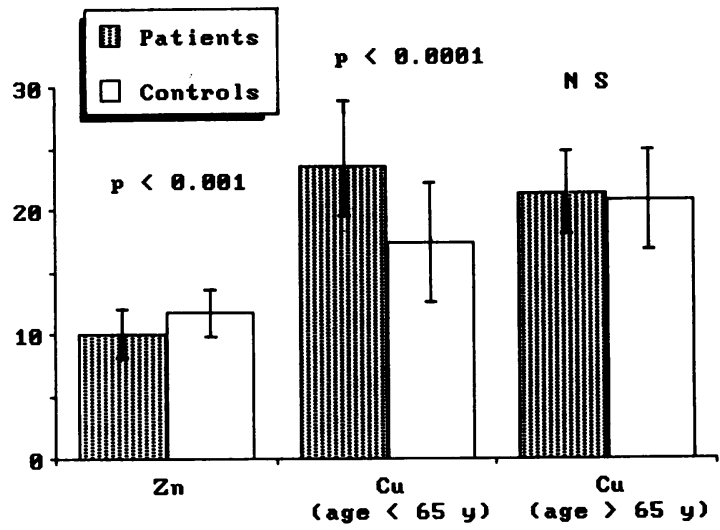

Fig. 1 Zinc and copper concentrations ( $\mu \mathrm{mol} / \mathrm{l})$ in the serum of patients with rheumatoid arthritis and in healthy. controls. Mean (SD). than in controls $(17.6(4.9) \mu \mathrm{mol} / \mathrm{l} ; \mathrm{p}<0.0001)$. In old ( $>65$ years) patients with RA the mean coppep. concentration was not significantly higher than that? in controls $(21.5(3.3) \mu \mathrm{mol} / 1 v 21.0(3.9) \mu \mathrm{mol} / \mathrm{l})$. I $\overrightarrow{\mathrm{F}_{3}^{*}}$ a more detailed analysis we found that the illness duration was not dependent on age. Likewise, the joint score index was no higher among elderly. patients. High copper concentrations were signifi cantly $(p<0.01)$ associated with treatment with slow acting disease modifying drugs, however. Treatmenfe with NSAIDs or low dose prednisone, or both, was most often used among patients over 65 years of age $(\mathrm{p}<0 \cdot 01)$.

PREDICTION OF VARIATION IN SERUM ZIN AND COPPER CONCENTRATIONS

Table 2 shows the independent variables with $\overrightarrow{0}$ predictive value for serum zinc concentration; nineo variables together predicted $73 \%$ of the variation $i \vec{m}$ serum zinc. The most prominent predicting varis ables were the joint score index, Waaler-Rose titreand haemoglobin. Table 2 shows six variables whic predict the variation in serum copper. The besit predictive independent variables for copper wer⿳⺈ age and erythrocyte sedimentation rate (ESR).

\section{Discussion}

Different variables reflecting the extent and severtits of RA were good predictors for serum zinc conceno tration. The joint score index was the most signiff cant independent variable, predicting $39 \%$ of variæ tion in serum zinc, and, conversely, the variation if serum zinc predicted $36 \%$ of the joint score index Rheumatoid factor titre, seropositivity, haemoglo? bin, and CRP were also among the nine variable $\overrightarrow{88}$ which together predicted $73 \%$ of the serum zin variation. Our results thus indicate an associatio between the extent and severity of the immunes

Table 2 Independent variables predicting zinc and serum copper values. Analysis using BMDP-UCLA 1985 program in forward stepwise multiple linear regression analysis

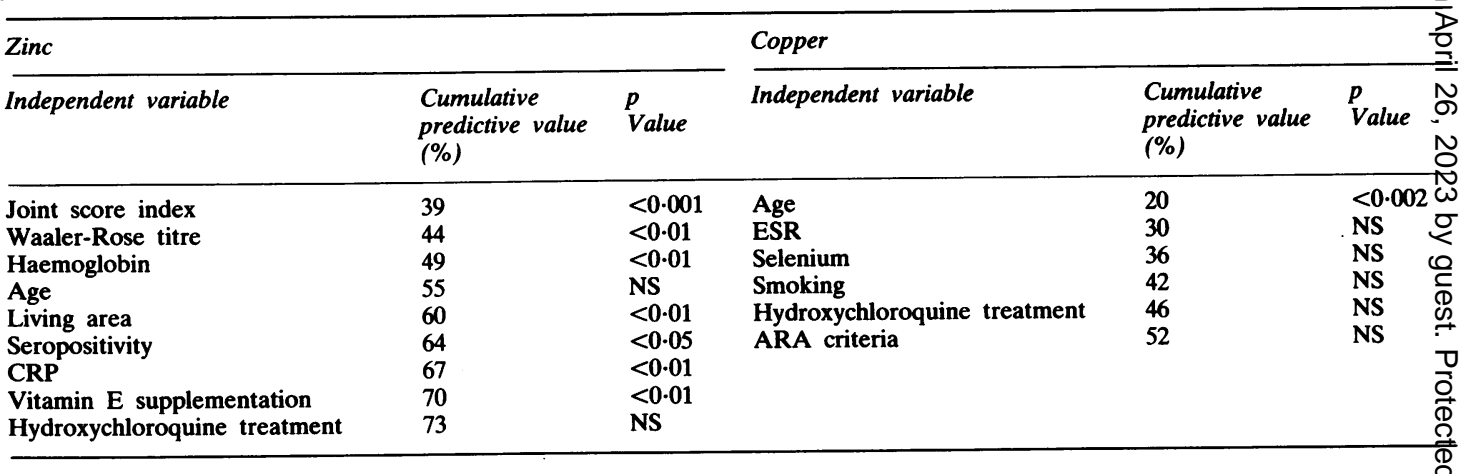


inflammatory rheumatoid process and serum zinc concentration.

It was noteworthy that CRP, though a good measure of the acute phase response, had an independent predictive value of only $3 \%$. Therefore, metallothionein mediated sequestration in the liver, induced by interleukin 1, is not an important explanatory factor in the cross sectional study of chronic inflammation, ${ }^{56}$ which is in contrast with the short term, acute phase response caused, for instance, by microbial invasion.

Our results confirm those of earlier work, which demonstrated low serum zinc and increased serum copper in rheumatoid arthritis. ${ }^{13-16}$ Serum copper had no independent predictive value for serum zinc, however, and serum zinc had none for serum copper. Therefore our work suggests that mechanisms other than gastrointestinal metallothionein and serum caeruloplasmin, both induced by low serum zinc, are responsible for these opposite changes in zinc and copper concentrations. Our results suggest rather that low serum zinc and high serum copper in RA reflect a myriad of changes in various mediators and body constituents (see also Table 1). Our work provides a solid basis for the prediction of the concentrations of these trace elements and may also give an indication of the sites and mechanisms with which they may be involved in RA, such as impaired $\mathrm{T}$ cell mediated immunity ${ }^{17}$ in synovial tissue and hyperactive neutrophil function ${ }^{4}$ in synovial fluid.

This study was supported by the Finnish Academy of Sciences, The Sigrid Juselius Foundation, and by the Arthritis Foundation of Finland. Ms Laila Saarvo is thanked for technical assistance.

\section{References}

1 Brewer G J. Hill G M. Dick R D. Prasad A S. Cossack Z T. Interactions of trace elements: clinical significance. J Am Coll Nutr 1985; 4: 33-8.
2 Schwartz M. Role of trace elements and cancer. Cancer Res 1975: 35: 3481-7.

3 Prasad A S. Clinical and biomedical spectrum of zinc deficiency in human subjects. In: Prasad A S. ed. Clinical, biochemical and nutritional aspects of trace elements. New York: Alan R Liss, 1982: 3-62.

4 Beisel W R. The role of zinc in neutrophil function. In: Prasad A S. ed. Clinical, biochemical and nutritional aspects of trace elements. New York: Alan R Liss. 1982: 203-10.

5 Dinarello $\mathrm{C} A$. Interleukin-1 and the pathogenesis of the acute phase response. $N$ Engl J Med 1984: 311: 1413-8.

6 Youssef A A. Wood B. Baron D N. Serum copper: a marker of disease activity in rheumatoid arthritis. J Clin Pathol 1983; 36: 14-17.

7 Afifi A A. Azen S P. Statistical analysis. A computer oriented approach. 2nd ed. New York: Academic Press. 1979.

8 Ropes M W. Bennett G A. Cobb J, Jacox R. Jessar R A. 1958 revision of diagnostic criteria for rheumatoid arthritis. Bull Rheum Dis 1958: 9: 175-6.

9 Steinbrocker O. Tracger C H. Batterman E C. Therapeutic criteria in rheumatoid arthritis. JAMA 1949: 140: 659-62.

10 Kaarcla K. Prognostic factors and diagnostic criteria in carly rheumatoid arthritis. Scand J Rheumatol /Suppl] 1985; 57: 1-54.

11 Social groups. Finnish social insurance institution report. 1977.

12 Salmela S, Vuori E. Improved direct determination of copper and zinc in a single serum dilution by atomic absorption spectrophotometry. Atomic Spectroscopy 1984; 5: 146-9.

13 Balogh Z, El Ghobarey A F, Fell G S, Brown D H, Dunlop J, Dick W C. Plasma zinc and its relationship to clinical symptoms and drug treatment in rheumatoid arthritis. Ann Rheum Dis 1980; 39: 329-32.

14 Halliwell B, Gutteridge J M C. Oxygen toxicity, oxygen radicals, transition metals and disease. Biochem $J$ 1984; 219: $1-14$.

15 Simkin P A. Treatment of rheumatoid arthritis with zinc sulfate. In: Sorenson $\mathbf{J} \mathbf{R} \mathrm{J}$, ed. Inflammatory diseases and copper. Clifton, N J: Humana Press, 1982: 483-94.

16 Sorenson J R J. An evaluation of altered copper, iron, magnesium, manganese and zinc concentrations in rheumatoid arthritis. Inorganic Perspectives in Biology and Medicine 1978; 2: 1-26.

17 Good R A, Fernandes G, Garofalv J A, Cunningham-Rundles C, Iwata T, West A. Zinc and immunity. In: Prasad A S, ed. Clinical, biochemical and nutritional aspects of trace elements. New York: Alan R Liss, 1982: 189-202. 